\title{
Kekuatan Politik Dewan Adat Suku Dalam Pemilihan Kepala Daerah Serentak Tahun 2017 Di Kabupaten Jayapura
}

\author{
Masni Banggu ${ }^{1}$, Arie Purnomo ${ }^{2}$, Asriani $^{3}$ \\ ${ }^{1}$ Ilmu Pemerintahan, FISIP, Universitas Muhammadiyah Sorong \\ ${ }^{2}$ Ilmu Pemerintahan, FISIP, Universitas Muhammadiyah Sorong \\ ${ }^{3}$ Ilmu Politik, FISIP, Universitas Sulawesi Barat \\ *Korespondensi: masnibanggu05@gmail.com
}

\begin{abstract}
This study aims to describe the political power of the Tribal Customary Council in providing support to regional head candidates in the 2017 Simultaneous Regional Head Elections in Jayapura Regency. This type of qualitative research with ethnographic type. Determination of informants is done purposively. Data was collected through interviews and literature review. The developed data describes, describes, and analyzes in detail the culture and customs based on the research objectives. The results showed that the nine Tribal Customary Councils in Jayapura Regency supported the candidate for Regent Mathius Awaitouw for the 2017-2022 period. The Tribal Customary Council (DAS) has a strong influence on the lives of local people, so that in the election of regional heads, the watershed is often the place where candidates for regional heads ask for permission and blessing.
\end{abstract}

Keywords: Strength, Politics, Council, Custom, Tribe, Pilkada

\begin{abstract}
ABSTRAK
Penelitian ini bertujuan untuk menggambarkan kekuatan politik Dewan Adat Suku dalam memberikan dukungan pada calon kepala daerah dalam Pilkada Serentak tahun 2017 di Kabupaten Jayapura. Jenis penelitian kualitatif dengan tipe etnografi. Penentuan informan dilakukan secara purposive. Pengumpulan data dilakukan melalui wawancara dan kajian pustaka. Data dikembangkan menjelaskan, menguraikan dan menganalisis secara rinci budaya dan adat istiadat berdasarkan tujuan penelitian. Hasil penelitian menunjukan bahwa kesembilan Dewan Adat Suku yang ada di Kabupaten Jayapura mendukung calon Bupati Mathius Awaitouw untuk periode 2017-2022. Dewan Adat Suku (DAS) memiliki pengaruh yang cukup kuat dalam kehidupan masyarakat setempat sehingga dalam pemilihan kepala daerah seringkali DAS menjadi tempat para calon-calon kepala daerah untuk meminta ijin dan restu.
\end{abstract}

Kata Kunci: Kekuatan, Politik, Dewan, Adat, Suku, Pilkada

PENDAHULUAN

Pemilihan kepala daerah Kabupaten Jayapura tahun 2017 menghadirkan lima 
pasangan calon. Pasangan calon yang memenuhi syarat sesuai yang ditetapkan oleh KPU Kabupaten Jayapura Nomor 74/Kpts/KPU-Kab.Jpr/030.434090/2016

tentang penetapan nomor urut dan daftar pasangan calon sebagai peserta dalam Pemilihan Bupati dan Wakil Bupati Kabupaten Jayapura Tahun 2017 tanggal 25 Oktober 2016 yakni sebagai berikut; 1) Yanni, SH dan Zadrak Afasedanya, SP (diusung oleh Partai GERINDRA, PAN dan PKB); 2) Mathius Awaitouw, SE, M.Si dan Giri Wijayantoro (diusung oleh Partai NASDEM, HANURA dan DEMOKRAT);

3) Godlief Ohee dan Drs. Frans Gina (jalur perseorangan); 4) Siska Yoku, SH dan Marselino Waromi (jalur perseorangan); 5) Jansen Monim, ST, MM dan H. Abdul Rahman Sulaiman, SE (diusung oleh Partai PDI-Perjuangan, GOLKAR dan PKS).

Syarat menjadi kepala daerah di Papua dan Papua Barat, salah satunya adalah terverifikasi sebagai orang asli Papua. Syarat ini berdasarkan Pasal 12 undang-undang nomor 21 tahun 2001 tentang Otonomi Khusus Bagi Provinsi Papua. Salah satu penentu kelancaran pelaksanaan tahapan pemilihan umum kepala daerah Gubernur di daratan Papua adalah rekomendasi Majelis
Rakyat Papua (MRP) mengenai syarat kandidat sebagai orang asli Papua. Walaupun dalam undang-undang otonomi khusus Papua hanya Gubernur dan Wakil Gubernur yang harus orang asli Papua, untuk posisi Bupati dan Walikota tak diatur dalam undang-undang tersebut. Namun secara tidak tertulis, jabatan Bupati dan Walikota lebih diutamakan bagi orang asli Papua.

Pemilihan Bupati dan Wakil Bupati Tahun 2017 di Kabupaten Jayapura, sejumlah tokoh adat (Ondoafi) yang tergabung dalam DAS (Dewan Adat Suku) menyatakan dukungan terhadap pasangan calon Mathius Awaitouw (calon Bupati Incumbent) dan Giri Wijayantoro. Ondofolo dari Sentani Timur hingga Sentani Barat, Moi, dan Waibhu berkomitmen memberikan dukungan penuh kepada pasangan calon Bupati dan Wakil Bupati Jayapura Mathius Awoitauw dan Giri Wijayantoro (MARIO), di pendopo Ondoafi Frans Alberth Yoku di Sentani, Jumat (27/1/2017). Dalam sambutannya, Ondofolo Kampung Ifar Besar, Frans Alberth Yoku, mengatakan bahwa sebelum gema Pilkada dicanangkan, dirinya sudah menaruh pilihan pada sosok Mathius Awoitauw, sehingga dirinya tidak melakukan aksi dukungan kepada kandidat 
lain selain Paslon MARIO (Yuliana Latinpo dalam JUBI. com 30/012017).

Dukungan juga datang dari Ondoafi se-Distrik Ravenirara Kabupaten Jayapura terhadap Mathius Awoitauw. Dukungan tersebut disampaikan oleh Ketua Dewan Adat Suku Imbi Numbay, Daniel Toto bahwa kami tokoh-tokoh adat mulai dari pesisir Ormu sampai wilayah Demta, khususnya Ondoafi se-Distrik Raveni Rara baik itu Ondoafi dari Ormu Nakatawa, Ormu Wari, Yongsu Desoyo dan Yongsu Spari, tidak ragu-ragu dalam mendukung Mathius Awoitauw untuk terpilih kembali menjadi Bupati Jayapura untuk periode kedua (Wartaplus.com 29/09/2016). Dewan Adat Suku juga dengan tegas menolak bakal calon Bupati Yanni (Calon Bupati nomor urut 1) dan Siska Yoku (calon Bupati nomor urut 4) karena bertentangan dengan adat di Kabupaten Jayapura.

Semua orang berhak untuk mencalonkan diri dalam Pemilihan Kepala Daerah tetapi untuk Kabupaten Jayapura masih tetap mengedepankan sistem patrilineal, kearifan lokal dan budaya. Sistem kepemimpinan adatnya dikenal dengan Ondoafi, tidak ada Ondoafi yang menyembah kepada perempuan (Pasifik.com 06/10/2016). Para tokoh adat mengingatkan bahwa Kabupaten Jayapura adalah wilayah dengan kekuasaan adat, ketua adat atau pemimpin adat berperan besar dalam wilayah dan masyarakatnya, sehingga harus menghormati aturan adat istiadat yang telah ada.

\section{METODE PENELITIAN}

Penelitian ini dilaksanakan di Kabupaten Jayapura, fokus penelitian Dewan Adat Suku. Penelitian ini menggunakan pendekatan kualitatif dan jenis penelitian yang digunakan adalah etnografi. Teknik pengumpulan data yang digunakan adalah teknik wawancara dan kajian pustaka. Penulis melakukan wawancara dengan para informan yang dianggap mempunyai kapasitas dan otoritas untuk menjelaskan mengenai Dewan Adat Suku. Kajian pustaka dengan mengumpulkan data dan informasi dari buku, jurnal penelitian dan pembahasan Dewan Adat serta Ondoafi yang pernah berkembang dan telah di dokumentasikan.

\section{HASIL DAN PEMBAHASAN}

Dewan Adat Suku mendukung Mathius Awaitouw karena dianggap mewakili masyarakat adat, dia adalah sosok yang paling dikenal oleh Dewan Adat 
dikarenakan Mathius adalah seorang Ondoafi. Keondoafiannya berasal dari kampung Phuay, yang merupakan salah satu dari kampung di Sentani Timur. Posisi Mathius sebagai Ondoafi tentunya mempunyai pengaruh terhadap para pendukungnya. Kelima pasangan calon yang maju dalam pemilihan kepala daerah tahun 2017 di Kabupaten Jayapura, hanya Mathius Awaitouw yang merupakan Ondoafi walaupun ada tiga calon Bupati lainnya (Godlief Ohee, Siska Yoku dan Jansen Monim) yang bermarga asli masyarakat Kabupaten Jayapura.

Status sosial Mathius yang merupakan anak adat juga sebagai Ondoafi di kampungnya berpengaruh terhadap dukungan yang diperolehnya dari Dewan Adat. Dari kelima pasangan calon yang maju, hanya Mathius yang mempunyai status sosial dalam masyarakat Kabupaten Jayapura sebagai Ondoafi. Dalam sumber kekuasaan, status sosial yang tinggi seperti kasta, keturunan cikal bakal pendiri kampung ataupun keturunan bangsawan dapat dijadikan sebagai sumber pengaruh tertutama dalam masyarakat yang masih menganut status sosial (Surbakti,2013:82).
Di Kabupaten Jayapura, status sosial tertinggi dipegang oleh Ondoafi. Ondoafi merupakan pemimpin adat tertinggi yang memiliki wewenang dalam semua kehidupan masyarakat di kampung. Status ini diperolehannya secara pewarisan, yang oleh masyarakat adat dimaknai sebagai bentuk penghormatan, pelaksanaan aturanaturan dan upaya menjauhkan semua larangannya. Ondoafi adalah pemegang garis keturunan yang di tarik melalui garis lurus dengan pendiri kampung dan adalah anak laki-laki sulung Ondoafi sebelumnya.

Dewan Adat Suku mendukung Mathius karena dia merupakan tokoh yang peduli terhadap masyarakat adat, yakni peduli tentang kegiatan apa saja yang dilakukan masyarakat adat atau segala bentuk tujuan yang membangun masyarakat adat. Sebelum menjadi Bupati Jayapura periode 2012-2017, Mathius Awaitouw telah lama bergabung dalam lembaga swadaya masyarakat. Mathius mempunyai visi untuk membangun Jayapura yang berjati diri, sebagai gambaran terhadap kondisi masyarakat Jayapura yang senantiasa menjaga, melindungi, memberdayakan dan merestorasi keaslian karakteristik jati dirinya pada kehidupan sosial, ekonomi, budaya dan 
pemerintahan mulai dari level kampung, distrik hingga kabupaten. Sedangkan misi yang berkaitan dengan masyarakat adat yakni dengan memperkuat hak-hak adat dan memberdayakan masyarakat berkelanjutan. Ini menjadi penting bagi peningkatan akses masyarakat berpartisipasi dalam seluruh rangkaian proses pembangunan di daerah. Salah satu komponen masyarakat yang dipandang memiliki otoritas nyata di tengah masyarakat adalah eksistensi adat.

Dewan Adat Suku (DAS) dibentuk di tahun 2002, karena kebangkitan lembagalembaga adat paling banyak dipengaruhi oleh penerapan undang-undang otonomi daerah pada tahun 2001. DAS dibentuk dengan tujuan agar nilai-nilai budaya tidak hilang dan adat istiadat dalam sistem kepemimpinan Ondoafi sejak dahulu tetap bertahan di tengah-tengah masyarakat yang modern. Kemudian mendapat pengakuan secara hukum melalui Surat Keputusan Bupati nomor 319 tahun 2014.

Berdasarkan surat keputusan Bupati nomor 319 tahun 2014 menetapkan; mengakui sembilan wilayah masyarakat hukum adat di kabupaten Jayapura yaitu DAS Sentani, DAS Moi, DAS Tepra, DAS imbi-numbai, DAS Yokari, DAS Jowwari, DAS Demutru, DAS Elseng dan DAS Oktim. Dewan Adat berperan membantu pemerintah daerah dalam menyelesaikan beragam persoalan khususnya sengketa kepemilikan hak ulayat. Kegiatan-kegiatan pembangunan oleh pemerintah dan pihak luar wilayah adat suku harus memperoleh persetujuan yang mengikat secara hukum dari Dewan Adat Suku (DAS) dan memfasilitasi masyarakat untuk berbicara dengan pemerintah. Hal inilah yang menjadi dasar pertimbangan Dewan Adat Suku mendukung Mathius dalam Pilkada Kabupaten Jayapura tahun 2017 karena pengakuan yang telah diberikan secara hukum mengakui sembilan wilayah masyarakat hukum adat.

Para pemimpin adat (Ondoafi) yang juga tergabung dalam Dewan Adat Suku juga secara personal menyatakan dukungannya terhadap Mathius karena selain pengakuan secara hukum terhadap Dewan Adat di sembilan wilayah adat, pemerintah daerah juga telah mensahkan peraturan daerah nomor 8 tahun 2014 tentang kampung. Dalam peraturan daerah tersebut pasal 2 ayat (1) Kampung terdiri dari Kampung dan Kampung Adat, (2) Kampung sebagaimana dimaksud pada ayat 
(1) merupakan kampung yang berpenduduk campuran, (3) Kampung Adat merupakan kampung yang beranggotakan masyarakat adat setempat dan memberlakukan peraturan-peraturan adat dalam kehidupan masyarakat.

Peraturan daerah nomor 8 tahun 2014 pasal 2 ayat 3 merupakan pengakuan kembali atau mengembalian jati diri pemerintahan Ondoafi di kampung adat. Kampung Adat atau YO dalam bahasan Sentani dan Tepra atau sebutan lainnya dalam bahasa suku-suku asli di Kabupaten Jayapura adalah kesatuan masyarakat hukum adat yang mempunyai satu kesatuan tradisi dan tata krama pergaulan secara turun termurun serta mempunyai wilayah tertentu dan berhak mengurus rumah tangganya sendiri berdasarkan adat istiadat yang dianut.

Peraturan daerah tersebut mengakui secara hukum kewenangan Ondoafi sebagai pemimpin kampung adat. Artinya, semua kewenangan Ondoafi yang meliputi bidang keagamaan, sosial, ekonomi dan peradilan yang berlaku di masa kepemimpinnya dulu akan diterapkan kembali lagi berdasarkan adat istiadat yang dianut. Kampung adat dipimpin oleh seorang Ondoafi, yang menurut ketentuan adat diabsahkan oleh garis keturunan yang ditarik melalui garis lurus dengan pendiri kampung dan adalah anak laki-laki sulung Ondoafi sebelumnya. Seorang Ondoafi mempunyai perangkat pembantu khusus yang disebut abu-afa. Peranan perangkat tersebut adalah sebagai penasihat utama bagi ondoafi dalam hal memberikan nasihat dan pertimbangan kepada ondoafi sebelum membuat suatu keputusan penting. Di samping itu abu-afa juga berperan sebagai juru bicara Ondoafi.

Mathius sebagai calon incumbent mempunyai kedudukan atau posisi sebagai orang nomor satu di pemerintahan daerah kabupaten Jayapura. Kekuasaan yang bersumber dari kedudukan atau posisi merupakan sumber pengaruh yang efektif (Surbakti, 2013:82). Kekuasaan yang bersumber dari kedudukan dimaksudkan kepada sesorang atau sekelompok orang karena yang bersangkutan menduduki posisi, sehingga dengan otomatis seseorang atau sekelompok yang memiliki kekuasaan tergantung seberapa tinggi kedudukan atau posisi yang dimilikinya, semakin tinggi kedudukanya maka semakin besar pula kekuasaan yang berada pada genggamanya. 
Mathius memiliki kekuasaan untuk menetapkan suatu peraturan atau kebijakan yang berkaitan dengan kepentingan masyarakatnya. Masyarakat akan mengenalnya sebagai seorang yang pernah berbuat untuk kepentingan masyarakat, walaupun kepentingan masyarakat ini masih bisa diperdebatkan. Namun setidaknya, selama masa kepemimpinannya berbagai kebijakan dan program telah diimplementasikan. Khususnya kebijakan yang berkaitan dengan masyarakat adat, Mathius memberikan ruang kepada masyarakat adat untuk memanfaatkan sumber daya alamnya.

Posisi atau kedudukan Mathius sebagai calon incumbent mempunyai pengaruh terhadap Dewan Adat Suku juga kepada masyarakat. Dalam mendistribusikan sumber-sumber kekuasaan, setiap masyarakat memiliki persepsi dan penilaian yang berbeda-beda terhadap sumber kekuasaan. Sejumlah kelompok masyarakat memandang sumber kekuasaan jabatan atau posisi lebih dihargai dari pada sumber kekuasaan normatif sehingga posisi atau jabatan mempunyai pengaruh yang lebih besar (Surbakti, 1995:87). Dewan Adat Suku mendukung Mathius karena posisinya sebagai calon incumbent di antara pasangan calon lainnya. Kebijakan yang dibuat oleh Mathius untuk mengembalikan kembali kampung adat dan mengakui secara hukum kewenangan Ondoafi, membuat Dewan Adat Suku memberikan dukungan penuh kepadanya sebagai calon Bupati periode 2017-2022.

Dewan Adat Suku memiliki kepentingan dalam mendukung Mathius Awaitouw pada pemilihan kepala daerah tahun 2017 yakni agar relasi -relasi Dewan Adat Suku dengan Mathius Awaitouw sebagai calon incumbent tetap terjaga dan saling mendukung. Dukungan yang diberikan tidak lepas dari berbagai kebijakan yang dirasakan langsung oleh DAS dan masyarakat adat melalui pengakuan sembilan wilayah masyarakat hukum adat dan kampung adat. Dewan Adat Suku memperoleh pengakuan secara hukum di masa kepemimpinan Mathius periode 2012-2017 yang menguntungkan posisinya sebagai mitra kerja pemerintah daerah dalam hal pembangunan. Sehingga sebagai pertukarannya, ketika Mathius mencalonkan kembali lagi pada Pilkada tahun 2017, maka Dewan Adat Suku sepakat untuk memberikan dukungan penuh kepadanya 
agar dapat terpilih kembali lagi sebagai Bupati Jayapura.

Dewan Adat Suku karena perkembangan zaman dan dipengaruhi oleh konteks lain dalam hal ini terkait persoalan politis menyebabkan Dewan Adat bertranformasi menjadi lembaga kepentingan. Hal tersebut dikarenakan Dewan Adat Suku selain memiliki posisi strategis pada masyarakat adat juga memiliki relasi yang kuat terhadap pemegang kekuasaan di Kabupaten Jayapura, karena pemegang kekuasaan menjaga eksistensi Dewan Adat Suku, relasi kepentingan tersebut juga menjadi dasar kenapa Dewan Adat Suku tersebut mendukung pasangan Mathius Awaitouw dan Giri Wijayantoro (MARIO).

Dewan Adat Suku mempunyai andil dalam pemilihan kepala daerah juga pemilihan legislatif di Kabupaten Jayapura. Mereka menginginkan bahwa orang-orang yang duduk di pemerintahan formal merupakan anak-anak adat atau masyarakat adat. Khusus untuk pemimpin formal atau Bupati, Dewan Adat Suku mengharapkan bahwa yang maju menjadi calon adalah anak-anak adat atau putra daerah Jayapura.
Dewan Adat menghimbau kepada masyarakat bahwa pencalonan ibu Yanni yang non Papua atau bukan putra-putri asli Kabupaten Jayapura walaupun dalam undang-undang tidak melarang pencalonannya tetapi tidak sesuai dengan adat istiadat yang dianut. Menurut adat istiadat dalam sistem kepemimpinan Ondoafi, yang menjadi seorang pemimpin adalah seorang laki-laki dan bukan perempuan. Ketika Ondoafi dan para Khoselonya rapat di dewan adat, perempuan tidak pernah hadir untuk mendengarkan rapat tersebut. Hadir saja tidak apalagi harus memberikan kesempatan untuk berbicara. Perempuan hanya bertugas untuk mengurus makanan saat rapat dan yang akan mengantarkan makanan ke pendopo adalah Abhu-akho.

Dewan Adat Suku yang berfungsi menjaga agar sistem kepemimpinan Ondoafi tetap dihormati dan diakui sebagai aturan adat istiadat di kabupaten Jayapura, membuat para perempuan yang mencalonkan diri sebagai wakil rakyat atau calon legislatif di DPRD Kab. Jayapura, banyak yang gagal atau tidak terpilih karena sistem kepemimpinan Ondoafi. Dari 25 kursi di DPRD Kabupaten Jayapura, hanya 
satu orang perempuan yang terpilih menjadi anggota legislatif di tahun 2014. Dalam pemilihan kepala daerah/Bupati sebelumnya juga pasangan calon yang ikut dalam Pilkada tidak ada calon perempuan. Menurut Bapak Daniel Toto (wawancara 29/08/2017), ketika perempuan terpilih menjadi pemimpin atau wakil rakyat di DPRD, dia akan turun ke masyarakat yang juga nantinya akan berbicara dengan para Ondoafi di kampung. Sedangkan dalam aturan adat, perempuan tidak diperbolehkan untuk masuk dalam pendopo Ondoafi, menurutnya adat itu tertulis atau tidak tetap harus dipatuhi oleh masyarakat.

Dewan Adat Suku memberikan pemahaman kepada masyarakat bahwa seharusnya dalam pencalonan pemimpin formal atau Bupati tidak boleh ada calon perempuan apalagi dia non Papua. Kekuasaan yang dikemukakan oleh Charles F. Andrain (dalam Haryanto, 2005:5) bahwa dapat didefinisikan sebagai penggunaan sejumlah besar sumber daya (aset, kemampuan) untuk memperoleh kepatuhan (tingkah laku menyesuaikan) dari orang lain. Dewan adat berusaha memperoleh kepatuhan dari anggota masyarakatnya melalui sumber daya yang dimiliki. Dewan
Adat Suku menyampaikan kepada masyarakat bahwa Kabupaten Jayapura menganut sistem kepemimpinan Ondoafi sehingga hanya membenarkan seorang lakilaki yang menjadi kepala daerah. Sistem kepemimpinan Ondoafi telah diakui dalam peraturan daerah nomor 8 tahun 2014 sehingga menurut Dewan Adat tidak ada pemimpin adat yang tunduk terhadap seorang perempuan.

Dalam undang-undang pemilihan kepala daerah siapa saja bisa mencalonkan diri dalam pemilihan sesuai syarat yang ditetapkan oleh penyelenggara pemilihan kepala daerah. Tidak ada aturan yang membedakan apakah dia calon perempuan atau calon laki-laki. Hal ini karena dukungan yang mereka berikan untuk memenangkan pasangan Mathius Awoitauw dan Giri Wijayantoro (MARIO) di Pilkada Kabupaten Jayapura khususnya Mathius Awoitauw sebagai Ondoafi yang juga merupakan anggota dari Dewan Adat Suku. Walaupun tidak ada aturan dalam peraturan seperti yang dijelaskan di atas, tetapi hal ini juga yang menyebabkan suara Yanni, calon Bupati yang dianggap memiliki modal finansial yang kuat dan merupakan saingan kuat dari pasangan MARIO tidak signifikan 
pada Pilkada Kabupaten Jayapura dan berada di posisi ketiga di wilayah adat Sentani, apa yang terjadi pada Yanni ini juga terjadi pada Siska Yoku, yang walaupun anak adat Sentani tetapi tetap di tolak oleh Dewan Adat karena faktor seorang calon Bupati perempuan.

Untuk Dewan Adat Suku Moi, mereka membuat surat pernyataan yang menyatakan dukungan masyarakat wilayah adat Moi kepada Mathius. Selain masyarakat adat asli Jayapura, DAS juga melibatkan perkumpulan atau kerukunan masyarakat lainnya untuk mendukung Mathius dalam Pilkada di Jayapura. Menurut Zakaria Done (wawancara 30/08/2017), masyarakat transmigrasi aman-aman saja dalam berdagang dan tinggal di wilayah Moi. Dalam program-program Mathius juga masyarakat transmigrasi juga diperhatikan dan dilibatkan.

Ondoafi merupakan pemimpin adat tertinggi yang memiliki wewenang dalam semua kehidupan masyarakat di kampung. Status ini diperolehannya secara pewarisan, yang oleh masyarakat adat dimaknai sebagai bentuk penghormatan, pelaksanaan aturanaturan dan upaya menjauhkan semua larangannya. Dalam sumber kekuasaan Adrain (dalam Narwis, 2013:17) kepatuhan masyarakat terhadap pemimpin adatnya atau Ondoafi karena sumber kekuasaan normatif yang dimilikinya.

Pemimpin adat atau Ondoafi ditaati oleh anggota masyarakatnya karena adat dan tradisi yang dipelihara dan ditegakkan oleh pempinnya. Dalam hubungan kekuasaan normatif, anggota masyarakat mengakui bahwa pemimpin atau organisasi/kelompok mempunyai hak untuk mengatur perilaku masyarakatnya. Kepercayaan ini telah berakar dipelihara secara terus menerus dalam masyarakat. Masyarakat percaya bahwa apa yang menjadi pilihan Ondoafi demi kepentingan bersama. Sehingga apa yang disampaikan oleh pemimpin adatnya/Ondoafi, maka akan diikuti oleh masyarakatnya. "B mengakui bahwa A mempunyai hak moral untuk mengatur perilaku B atau masyarakat mengakui bahwa Dewan Adat Suku mempunyai hak atau memiliki kekuasaan untuk mengatur masyarakat.

\section{SIMPULAN}

Berdasarkan hasil penelitian dan pembahasan pada bagian sebelumnya, maka hal yang dapat disimpulkan oleh penulis, 
yaitu Dewan Adat Suku mendukung calon Bupati Mathius Awaitouw karena Mathius merupakan seorang Ondoafi yang juga anggota dari Dewan Adat Suku dan Mathius merupakan calon incumbent yang dikenal oleh masyarakat dibandingkan kandidat yang lain sekaligus penentu kebijakan. Dewan Adat Suku memiliki pengaruh di lingkungan masyarakat sehingga dapat menjadi opinion leader bagi masyarakat dan tempat para calon kepala daerah untuk meminta restu.

\section{DAFTAR PUSTAKA}

Budiardjo, Miriam. 2006. Dasar-Dasar llmu Politik. Gramedia Pustaka Utama, Jakarta: Cetakan kedua puluh sembilan

2008. Dasar-Dasar 1lmu Politik (edisi revisi), Jakarta: PT. Gramedia Pustaka Utama:

Huntington. Samuel \& Joan M. Nelson. 1984. No Easy Choice, Political Participation in Developing Countries Cambridge, Mass: Harvard University Press, 1976 (diterjemahkan oleh Hasan Basari). Jakarta. PT. Sangkala Pulsar.

Jamie S. Davidson, David Henley dan Sandra Moniaga. 2010. The Revival of Tradition in Indonesian Politics: The Deployment of Adat from Colonialism to Indigenism: Adat Dalam Politik Indonesia. Jakarta: Yayasan Pustaka Obor Indonesia.
Mansoben, J.R. 1995. Sistem Politik Tradisional di Irian Jaya. Jakarta: LIPI

Ritzer, George dan J. Goodman, Douglas. 2004. Teori Sosiologi Moderen. Science: Jakarta: Kencana.

Surbakti, Ramlan. 2013. Memahami Ilmu Politik. Jakarta. CV. Prima Grafika

B. B. Bonefasius Bao, Kuatnya Kekuasaan Ondoafi di Tengah Masyarakat Urban (Studi Tentang Kekuasaan Ondoafi Kota Jayapura Papua). Politika: Jurnal Ilmu Politik, vol. 1, no. 2, pp. 46-58, May. 2013.

Narwis, Muhammad. 2013. Tesis. Dominasi Politik di Mandar (sebuah studi tentang Fenomena Tiga Klan di Kabupaten Polewali Mandar). Universitas Gadjah Mada.

Kendi Ibrahim. Artikel Analisis DAS (Kebijakan Revitalisasi Dewan Adat Sentani Sebagai Lembaga Representasi Kultur Masyarakat Adat Suku Sentani Di Kabupaten Jayapura). FISIP Universitas Cendrawasih. (di akses pada tanggal 12 April 2017 pukul 22.00

Lande,Juwita. 2011. Peran Lembaga Adat Masyarakat Toraja Dalam Meningkatkan Partisipasi Masyarakat Mengikuti Pemilihan Kepala Daerah (Pilkada) Di Kabupaten Toraja Utara. Universitas Hasanuddin.

Undang- undang Nomor 8 tahun 2015 tentang Perubahan Atas UndangUndang Nomor 1 Tahun 2015 tentang Penetapan Peraturan Pemerintah Pengganti Undang- 
Undang Nomor 1 Tahun 2014 tentang Pemilihan Gubernur, Bupati, Dan Walikota

Undang-undang Nomor 21 Tahun 2001 tentang Otonomi Khusus Bagi Provinsi Papua

Undang-undang Nomor 6 Tahun 2014 tentang Desa

Peraturan Menteri Dalam Negeri Nomor 52 tahun 2014 Tentang Pedoman Pengakuan Dan Perlindungan Masyarakat Hukum Adat

Peraturan Daerah Khusus Provinsi Papua Nomor 23 Tahun 2008 tentang Hak Ulayat Masyarakat Hukum Adat dan Hak Perorangan Warga Masyarakat Hukum Adat Atas Tanah

Peraturan Daerah Kabupaten Jayapura Nomor 8 tahun 2014 tentang Kampung

Surat Keputusan Bupati Jayapura Nomor 319 Tahun 2014 Tentang Pengakuan dan Perlindungan Masyarakat Hukum Adat di Kabupaten Jayapura

AntaraPapua.com " Tokoh Adat Sentani Siap Menangkan Yanni-Zadrak" (diakses pada tanggal 12 April 2017 pukul 19:00 wita)

Hendrik Palo. Sidang Adat II Dewan Adat Suku Moi Kabupaten Jayapura (dipubilkasikan di Papua Word.blogspot pada tanggal 09 November 2008) diakses pada tanggal 11 April 2017 Pukul 22.50 Wita

Jayapurakab.go.id (diakses pada tanggal 18 April 2017 pukul 23.07)
KABORA News. Dasar Organisasi Adat Di Papua, Legitimasi Atau Legalitas.(diakses pada tanggal 11 April 2017 pukul 21.46 wita)

Moch. Syahri. Working Paper (Teori Pertukaran George Homan dan Peter Blau). Pascasarjana Fisip Universitas Airlangga. (dipublikasikan di ResearchGate.com dan diakses tanggal 11 Mei 2018 Pukul 22.35)

Pilipus M. Kopeuw. Menggali Budaya Sentani Di Papua Untuk Indonesia "Dalam Agenda "Waktu Indonesia Timur"(Journey To The East) (dipublikasikan di Black Eagle's Blog tanggal 13 September 2013 dan diakses pada tanggal 06 April 2017 pukul 17.46)

Super User "Tak Ada Ondoafi Menyembah Perempuan"(dipublikasikan di Pasifik Pos.com pada tanggal Kamis, 06 Oktober 2016 12:52, di akses pada tanggal 23 April 2017 pukul 20.49 wita)

Yuliana Latinpo "Tokoh intelektual dan adat berkomitmen menangkan pasangan Mario"(dipublikasikan di JUBI.com Portal Berita Tanah Papua No.1 pada tanggal Senin, 30 Januari 2017 05:17 wib dan diakses pada tanggal 18 April 2017 pukul 22.30)

\section{PROFIL SINGKAT}

Masni Banggu S.IP., M.Si Lahir di Kota Bitung05 September 1989. Lulus sarjana (S1) dari program studi Ilmu Politik Universitas Hasanuddin Makassar tahun 2012. Kemudian melanjutkan Program 
Magister Ilmu Politik (S2) di Universitas Hasanuddin Makassar dan lulus di tahun 2018. Saat ini bekerja sebagai tenaga pengajar di Universitas Muhammadiyah Sorong. 